\title{
Prognostic Significance of P53 expression in various grades of Epithelial Dysplasia
}

\author{
Swati K Patil* \\ Department of Oral Pathology \& Microbiology, Datta Meghe Institute of Medical Sciences, India
}

Submission: April 06, 2020; Published: April 14, 2020

*Corresponding author: Department of Oral Pathology \& Microbiology, Swati K Patil, Datta Meghe Institute of Medical Sciences, India

\begin{abstract}
Background: Potentially malignant disorders (PMD) in oral mucosa represent the morphological steps of epithelial transformation in the form of various grades of dysplasia. Only few cases of dysplasia evolve into carcinoma, and there are no specific markers invented which can predict the probability of progression. Oral carcinogenesis is a multistage course which constitutes a sequence of molecular events resulting in cell cycle dysregulation. p53 is the most commonly affected tumour suppressor gene. p53 mutation leads to uncontrolled proliferation of cancer cells as well as increased p53 protein. p53 overexpression has been suggested to be consistent indicators for development of oral cancer. The objective of this study is to investigate p53 immunohistochemical expression in various grades of oral epithelial dysplasia and to estimate the correlations between their expression levels in various grades of dysplasia.
\end{abstract}

Methods: This study is done at the Dept of Oral Pathology \& Microbiology, SPDC, Wardha. Total four groups were taken. Ten patients each of mild, moderate and severe epithelial dysplasia i.e total-30 patients and 10 control patients. Sample size required for group was calculated by using required formula. P53 positive cells were counted in 5 HPF in all grades of epithelial dysplasia and labeling index was measured.

Results:

ANOVA test was applied to see the differences in the P53 expression.

It was found that-

LI was increased with the increasing grades of epithelial dysplasia (ED).

P53 expression was seen in 5 HPF in all grades of ED and it was observed that it is seen in basal cell layer in normal oral mucosa, basal and parabasal cell layers in mild ED and basal, parabasal and supra basal layers in moderate and severe grades of ED in focal areas.

Conclusion: The increase in the p53 expression in epithelium correlates to various grades of epithelial dysplasias.

Keywords: P53; Epithelial dysplasia; Immunohistochemistry

Abbreviations: PMD: Potentially Malignant Disorders; IHC: Immunohistochemistry; ED: Epithelial Dysplasia; LI: Labeling Index; PPV: Positive Predictive Value

\section{Background}

Potentially malignant disorders (PMD) represent the morphological steps of epithelial transformation in the form of various grades of dysplasia, but only few cases of dysplasia evolve into carcinoma. There is no specific marker to identify the possibility of succession of dysplasia. Oral carcinogenesis is a multistage process with series of molecular events which may lead to cell cycle dysregulation [1]. p53 is the most commonly affected tumour suppressor gene. Normal p53 protein is difficult to be detected in normal tissues with short half-life of 6-20 minutes whereas changed protein has a half-life of about 6 hours which makes it easy to be detected by immunohistochemistry (IHC) in precancerous and cancerous lesions. p53 is a guardian of genome which controls the cell cycle progression from G1stage to S-stage. Alterations in p53 gene leads to uncontrolled proliferation of cancer cells with increased p53 protein causing dysfunction of regulatory mechanism during carcinogenesis [1]. p53 overexpression has been suggested to be consistent indicators for Oral Cancer development.

The objective of this study is

a) To assess the expression of p53 in various grades of epithelial dysplasia.

b) To compare expression of p53 in various stages of epithelial dysplasia. 


\section{Methods}

This study is carried out at the Dept of Oral Pathology \& Microbiology, SPDC, Wardha

a) Group A-10 patients each for mild, moderate and severe epithelial dysplasia. i.e. total-30 patients.

b) Group B -10 control patients.

Sample size $=(\mathrm{n})$ for each group. $\mathrm{n}$ is calculated by using following formula- $n=(Z \boldsymbol{\alpha} / 2+Z \boldsymbol{\beta})^{2 * 2 *} \sigma^{2} / d^{2}$

In above formula $\mathrm{Z} \boldsymbol{\alpha} / 2=$ is the critical value of normal distribution at $\alpha / 2$ (e.g. for a confidence level $=95 \%, \alpha=0.05 \&$ critical value $=1.96), \mathrm{Z} \beta$ is the critical value of Normal distribution at $\boldsymbol{\beta}$ (e.g. for a power of $80 \% \boldsymbol{\beta}=0.2$ and critical value $=0.84$ ).

$\boldsymbol{\sigma}^{2}=$ population variance

$\mathrm{d}=$ difference you would like to detect.

Sample size for each group of this study was taken out by using above formula.

$$
\begin{aligned}
& \boldsymbol{\sigma}=2.5+1.9=4.4 / 2==2.2 \\
& \mathrm{~d}=12-9=3 \\
& \mathrm{n}=2 \times(2.2)^{2}(1.96+0.84)^{2} / 3^{2} \\
& =2 \times 4.84 \times 7.84 / 9
\end{aligned}
$$

$=75.89 / 9$

$=8.43$ (nearer to 10 )

\section{Inclusion Criteria}

Subjects diagnosed with various grades of dysplasias histopathologically under microscope from the specimen received in our department from department of oral surgery and 10 control patients.

\section{Exclusion Criteria}

a) Patients with histopathologically diagnosed recurrence cases of oral squamous cell carcinomas.

b) Subjects having history of radiotherapy and chemotherapy.

c) Patients with history of any other systemic diseases.

Case history proforma was recorded for relevant information and observation. All the included cases, on the basis of histopathology were graded into different stages of epithelial dysplasia. like mild, moderate and severe. Immunohistochemistry (IHC) is carried out on paraffin embedded tissue blocks fixed with neutral buffered formalin to detect expression of P53. Interpretation of immunohistochemically stained section is carried out in five high power fields in highly stained areas. The

\begin{tabular}{|c|c|c|c|c|c|c|c|c|c|c|c|c|c|c|c|c|c|c|c|}
\hline $\begin{array}{l}\text { Patient's } \\
\text { number }\end{array}$ & Normal & & Mild ED & & & & Mean & & $\begin{array}{l}\text { Moderate } \\
\text { ED }\end{array}$ & & & & Mean & & & $\begin{array}{c}\text { Severe } \\
\text { ED }\end{array}$ & & & Mean \\
\hline $\begin{array}{c}\text { For each } \\
\text { group }\end{array}$ & OM & & $\begin{array}{c}\text { P53+VE } \\
\text { CELLS }\end{array}$ & & & & LI & & $\begin{array}{c}\text { P53+VE } \\
\text { CELLS }\end{array}$ & & & & LI & & & $\begin{array}{c}\text { P53+VE } \\
\text { CELLS }\end{array}$ & & & LI \\
\hline $1^{\text {st }}$ & 8 & 11 & 13 & 12 & 12 & 5 & 11 & 31 & 112 & 64 & 31 & 40 & 55.6 & 45 & 50 & 70 & 30 & 60 & 51 \\
\hline $2^{\text {nd }}$ & 0 & 20 & 28 & 35 & 10 & 11 & 21 & 26 & 27 & 25 & 21 & 15 & 22.8 & 42 & 40 & 36 & 60 & 45 & 45 \\
\hline $3^{\text {rd }}$ & 0 & 20 & 25 & 15 & 12 & 25 & 19 & 0 & 0 & 0 & 0 & 0 & 0 & 35 & 42 & 38 & 44 & 49 & 42 \\
\hline $4^{\text {th }}$ & 12 & 30 & 20 & 23 & 32 & 28 & 27 & 38 & 25 & 27 & 22 & 20 & 26.4 & 51 & 55 & 30 & 35 & 45 & 43 \\
\hline $5^{\text {th }}$ & 0 & 0 & 0 & 0 & 0 & 0 & 0 & 20 & 28 & 33 & 27 & 51 & 31.8 & 0 & 0 & 0 & 0 & 0 & 0 \\
\hline $6^{\text {th }}$ & 0 & 15 & 25 & 20 & 15 & 10 & 17 & 10 & 8 & 5 & 12 & 5 & 8 & 22 & 30 & 10 & 20 & 20 & 20 \\
\hline $7^{\text {th }}$ & 15 & 60 & 34 & 35 & 43 & 25 & 39 & 45 & 68 & 40 & 60 & 50 & 52.6 & 0 & 0 & 0 & 0 & 0 & 0 \\
\hline $8^{\text {th }}$ & 0 & 10 & 13 & 8 & 7 & 17 & 11 & 35 & 20 & 23 & 15 & 12 & 21 & 50 & 40 & 60 & 35 & 25 & 42 \\
\hline $9^{\text {th }}$ & 0 & 0 & 0 & 0 & 0 & 0 & 0 & 0 & 0 & 0 & 0 & 0 & 0 & 0 & 0 & 0 & 0 & 0 & 0 \\
\hline $10^{\text {th }}$ & 6 & 0 & 0 & 0 & 0 & 0 & 0 & 0 & 0 & 0 & 0 & 0 & 0 & 40 & 45 & 62 & 53 & 51 & 50 \\
\hline
\end{tabular}
expression of P53 and cellular morphological changes are noted in the epithelium (Tables 1-3).

Table 1: Labelling index in mild, moderate and severe epithelial dysplasia.

Table 2: P53 Immunopositive cells in 5 (HPF)in 10 patients of each group of epithelial dysplasia.

\begin{tabular}{|c|c|c|c|}
\hline Normal & Mild & Moderate & 56 \\
\hline 0 & 11 & 23 \\
\hline 0 & 21 & 0 & 45 \\
\hline 0 & 19 & 26 & 26 \\
\hline 0 & 27 & 43 & 42 \\
\hline
\end{tabular}




\begin{tabular}{|l|c|c|c|}
\hline 0 & 0 & 32 & 0 \\
\hline 0 & 17 & 8 & 20 \\
\hline 0 & 39 & 53 & 0 \\
\hline 0 & 11 & 21 & 42 \\
\hline 0 & 0 & 0 & 0 \\
\hline 0 & 0 & 0 & 50 \\
\hline
\end{tabular}

Table 3: Mean values of grades of epithelial dysplasias.

\begin{tabular}{|c|c|c|c|}
\hline Normal & Mild & Moderate & Severe \\
\hline 4.1 & 14.5 & 21.8 & 29 \\
\hline
\end{tabular}

\section{Results}

ANOVA test is applied to see the differences in the p53 expression.

It was found that

a) LI was increased with the increasing grades of epithelial dysplasia (ED).

b) p53 expression was seen in 5 HPF in all grades of ED and it was observed that it is seen in basal layer in normal mucosa, basal and parabasal layers in mild ED and basal, parabasal and supra basal layers in moderate and severe grades of ED in focal areas.

Mean of LI in various grades of epithelial dysplasia came as under in confirmity with other articles Takeda et al. [2].

\section{Discussion}

In this study, quantitative image analysis had demonstrated different expression patterns of p53 in various grades of oral epithelial dysplasia. With regard to 553 expression, progressive and significant increase was observed from mild to severe types of epithelial dysplasia as observed by Francesca et al. [3] and Juan C et al. [4]. The results told by Kerdpon et al 6 showed that there is no p53 expression in oral mucosa which is normal however in our studies 4 out of 10 patients showed p53 expression. It was expressed only in the basal cell layer in normal epithelium and expanded into the parabasal and superficial zones in grades of dysplasia as observed by Dong M Shin et al. [5]. Thus, we conclude that there are alterations in p53 in early phases of oral cancer. Thus, it may be an excellent biomarker in trials of chemoprevention. In our study mean labeling index (LI) had shown gradual increase from mild to moderate and then severe ED. Also, foci of p53positive expression were observed in moderate and severe dysplasia. Our findings are in accordance to Jennifer Kushner, Grace Bradley, Richard C \& K Jordan [6]; T Takeda et al. [2]. In our study LI pattern was found to be a useful index to assess the stage of epithelial dysplasia (Figures 1-3).
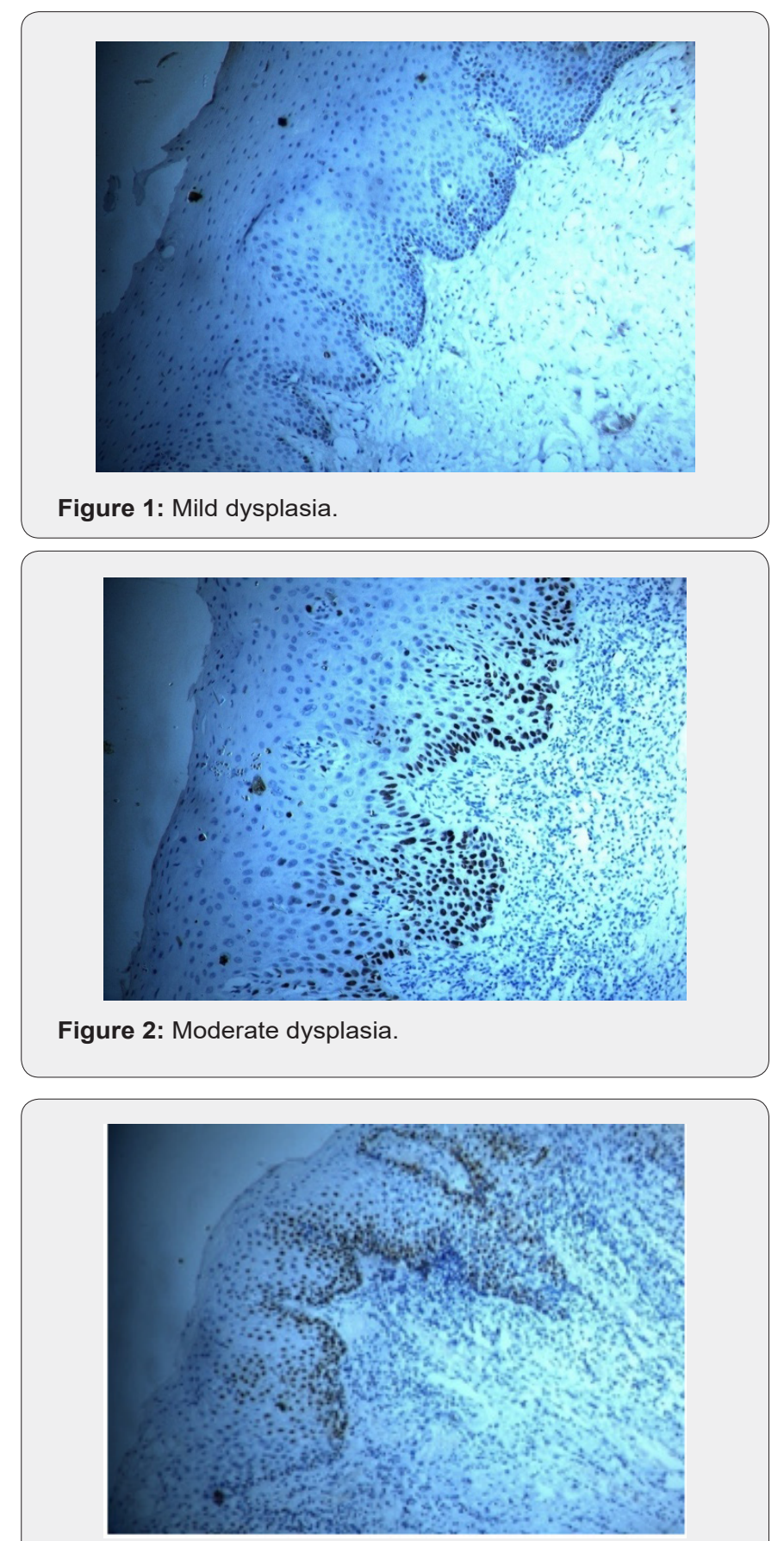

Figure 3: Severe dysplasia. 
Presence or absence of p53 in various grades of dysplasia could not be used to predict the outcome of precancerous lesions as stated by Alison M Rich et al. [7]. In the present study it was seen that $\mathrm{p} 53$ staining reported in the supra basal layer of epithelium is significantly associated with moderate and severe grades of dysplasia. This finding is in agreement with that of I Cruz et al. [8] where he concluded that specificity and positive predictive value (PPV) for malignant transformation of supra basal p53 staining was greater to the assessment of dysplasia, but sensitivity was lesser. Aline Correa et al. [9] and Reddy VM et al. [10] also found same results. Gayani Pitiyage, Tilakaratne WM et al. [11] studied p53 mutations in pre-cancerous lesions which can progress to cancer. Out of total cases examined p53 stabilization was observed in $50 \%$ of pre-cancerous lesions whereas few cases progressed to cancer. It is confirmed that $\mathrm{p} 53$ evaluation is not the criteria to say whether dysplasia is converting to cancer or not. Only clinical and histolopathological findings cannot give a hint whether precancerous lesions remain stable, relapse or progress to cancer. Dysplastic or non-dysplastic lesions may convert to invasive carcinomas. So, to channelize the management of these lesions molecular markers must be identified which can predict disease progression. Many studies have concluded that several genes or pathways are concerned with the alterations of normal mucosa to dysplastic one and finally to cancer. So, it is essential to study molecular changes in the biopsy tissues from large cohorts of subjects [11].

It can be inferred from the present study that gradual increase in positive p53 expression from mild to severe grades of epithelial dysplasia indicate a role of p53 in proliferative cells and transforming carcinoma. Positive or negative staining by p53 could not be used to predict the outcome of precancerous lesions. Our observations were similar to previous findings that expression of p53 could be used as a definite marker for lesions which can convert to malignancy. p53 as a prognostic marker may prove as an adjunct to histopathological estimation in the prognosis of precancerous lesions. However, further studies with larger sample size using a panel of related molecules like Ki 67, p16 etc. are necessary to establish the full potential of p53 as a prognostic marker in epithelial dysplasias [12-22].

\section{Conclusion}

i. The increase in the p53 expression in epithelium correlates to various grades of epithelial dysplasias. The clinical application in the community is that the increase in the p53 expression occurs as an early episode in oral carcinogenesis and would help in the early diagnosis and proper treatment for histopathologically diagnosed dysplastic cases in the community. Combination of P53 and Ki 67 is creditable in OSCC. However, P53 is a definite marker for active proliferation (Screening mechanism). Moderate and severe grades of ED are risky i.e. they have high potential to convert into malignancy so these patients should be kept under follow up. Larger sample size is required to study in detail.

\section{References}

1. Bina Raju, Ravi Mehrotra, Gunnvor Øijordsbakken, Ali K, AL-Sharabi, et al. (2005) Expression of p53, Cyclin D1 and Ki-67 in Pre-malignant and Malignant Oral Lesions: Association with Clinicopathological Parameters. Anticancer Research 25(6c): 4699-4706.

2. Takeda T, Sugihara K, Hirayama Y, Hirano M, Tanuma JI, et al. (2006) Immunohistological evaluation of Ki-67, p63, CK19 and p53 expression in oral epithelial dysplasias. J Oral Pathol Med 35: 369-375.

3. Francesca Angiero, Angiola Berenzi, Anna Benetti, Elisa Rossi, Rachele Del Sordo, et al. (2008) Expression of P16, P53 and Ki-67 Proteins in the Progression of Epithelial Dysplasia of the Oral Cavity. Anticancer Research 28: 2535-2540.

4. Juan C Cuevas González, Luis A Gaitán Cepeda, Socorro A Borges Yañez, Alejandro Donohué Cornejo, Ana D Mori Estévez, et al. (2016) p53 and p16 in oral epithelial dysplasia and oral squamous cell carcinoma: A study of 208 cases. Indian Journal of Pathology and Microbiology 59(2): 153-158.

5. Dong M Shin, Jhingook Kiln, Jae Y Ro, Jason Hittelman, Jack A, et al. (1994) Activation of p53 Gene Expression in Premalignant Lesions during Head and Neck Tumorigenesis. Cancer Research 54(2): 321326.

6. Kushner J, Bradley G, Jordan RC (1997) Patterns of p53 and Ki-67 protein expression in epithelial dysplasia from the floor of the mouth. J Pathol 183(4): 418-423.

7. Alison M Rich, Duangporn Kerdpon, Peter C Reade AM (1999) p53 expression in oral precancer and cancer. Australian Dental Journal 44(2): 103-105.

8. Cruz I, Napier SS, Van der Waal I, Snijders PJ, Walboomers JM, et al. (2002) Suprabasal p53 immunoexpression is strongly associated with high grade dysplasia and risk for malignant transformation in potentially malignant oral lesions from Northern Ireland. J Clin Pathol 55(2): 98-104.

9. Aline Correa Abrahao, Beatriz Venturi Bonelli, Fábio Daumas Nunes, Eliane Pedra Dias, Márcia Grillo Cabral (2011) Immunohistochemical expression of p53, p16 and hTERT in oral squamous cell carcinoma and potentially malignant disorders. Braz Oral Res 25(1): 34-41.

10. Reddy VM, Kamath A, Radhakrishnan RA (2012) p53 Immunoprofiling of potentially malignant oral disorders: A case series analysis. Indian J Cancer 49(1): 27-32.

11. Pitiyage G, Tilakaratne WM, Tavassoli M, Warnakulasuriya S (2009) Molecular markers in oral epithelial dysplasia: review. J Oral Pathol Med 38(10): 737-752.

12. Kerdpon D, Rich AM, Reade PC (1997) Expression of p53 in oral mucosal hyperplasia, dysplasia and squamous cell carcinoma. Oral Diseases 3(2): 86-92.

13. Gusterson BA, Anbazhagan R, Warren W, Midgely C, Lane DP, et al (1991) Expression of p53 in premalignant and malignant squamous epithelium. Oncogene 6(10): 1785-1789.

14. Regezi JA, Zarbo RJ, Regev E, Pisanty S, Silverman S, et al. (1995) P53 protein expression in sequential biopsies of oral dysplasias and in situ carcinomas. J Oral Pathol and Medicine 24(1): 18-22.

15. Raybaud-Diogène H, Tétu B, Morency R, Fortin A, Monteil RA (1996) p53 overexpression in head and neck squamous cell carcinoma: review of the literature. Eur J Cancer B Oral Oncol 32B(3):143-149. 
16. Murti PR, Warnakulasuriya KA, Johnson NW, Bhonsle RB, Gupta PC, et al. (1998) p53 expression in oral precancer as a marker for malignant potential. J Oral Pathol Med 27(5): 191-196.

17. Allan P Weston, Sushanta K Banerjee, Prateek Sharma, Trang M Tran BS, Robert Richards, et al. (2001) p53 protein expression in low grade dysplasia (LGD) in barrett's esophagus: Immunohistochemical marker predictive of progression. Am J Gastroenterol 96(5): 1355-1362.

18. Carme Mallofré, Mireia Castillo, Vanesa Morente, Manel Solé, (2003) Immunohistochemical Expression of CK20, p53, and Ki-67 as Objective Markers of Urothelial Dysplasia. Modern Pathology 16: 187-191.

19. Kövesi G, Szende B (2003) Changes in apoptosis and mitotic index, p53 and Ki67 expression in various types of oral leukoplakia. Oncology 65(4): 331-336.
20. Bortoluzzi MC, Yurgel LS, Dekker NP, Jordan RC, Regezi JA (2004) Assessment of p63 expression in oral squamous cell carcinomas and dysplasias. Oral Surg Oral Med Oral Pathol Oral Radiol Endod 98(6): 698-704.

21. Nishat Sultana, Shambulingappa Pallagatti, Ali Imam Mohamed (2011) P53 Expressions in Oral Submucous Fibrosis and Oral Squamous Cell Carcinoma. International Journal of Oral \& Maxillofacial Pathology 2(1): 9-14.

22. Elba-Rosa Leyva-Huerta, Constantino Ledesma-Montes, RebecaEstela Rojo-Botello, Elisa Vega-Memije (2012) P53 and bcl-2 immunoexpression in patients with oral lichen planus and oral squamous cell carcinoma. Med Oral Patol Oral Cir Bucal 17 (5): e745750 .

\section{Your next submission with Juniper Publishers} will reach you the below assets

- Quality Editorial service

- Swift Peer Review

- Reprints availability

- E-prints Service

- Manuscript Podcast for convenient understanding

- Global attainment for your research

- Manuscript accessibility in different formats

( Pdf, E-pub, Full Text, Audio)

- Unceasing customer service

Track the below URL for one-step submission https://juniperpublishers.com/online-submission.php 